\title{
RESEARCH
}

Open Access

\section{Integrating structure and function: mapping the hierarchical spatial heterogeneity of urban landscapes}

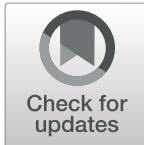

Yuguo Qian ${ }^{1,2}$, Weiqi Zhou ${ }^{1,2^{*}}$, Steward T. A. Pickett ${ }^{3}$, Wenjuan $\mathrm{Yu}^{1,2}$, Dingpeng Xiong ${ }^{4}$, Weimin Wang ${ }^{5}$ and Chuanbao Jing ${ }^{1,2}$

\begin{abstract}
Background: Cities are social-ecological systems characterized by remarkably high spatial and temporal heterogeneity, which are closely related to myriad urban problems. However, the tools to map and quantify this heterogeneity are lacking. We here developed a new three-level classification scheme, by considering ecosystem types (level 1), urban function zones (level 2), and land cover elements (level 3), to map and quantify the hierarchical spatial heterogeneity of urban landscapes.

Methods: We applied the scheme using an object-based approach for classification using very high spatial resolution imagery and a vector layer of building location and characteristics. We used a top-down classification procedure by conducting the classification in the order of ecosystem types, function zones, and land cover elements. The classification of the lower level was based on the results of the higher level. We used an objectbased methodology to carry out the three-level classification.

Results: We found that the urban ecosystem type accounted for $45.3 \%$ of the land within the Shenzhen city administrative boundary. Within the urban ecosystem type, residential and industrial zones were the main zones, accounting for $38.4 \%$ and $33.8 \%$, respectively. Tree canopy was the dominant element in Shenzhen city, accounting for $55.6 \%$ over all ecosystem types, which includes agricultural and forest. However, in the urban ecosystem type, the proportion of tree canopy was only $22.6 \%$ because most trees were distributed in the forest ecosystem type. The proportion of trees was $23.2 \%$ in industrial zones, $2.2 \%$ higher than that in residential zones. That information "hidden" in the usual statistical summaries scaled to the entire administrative unit of Shenzhen has great potential for improving urban management.

Conclusions: This paper has taken the theoretical understanding of urban spatial heterogeneity and used it to generate a classification scheme that exploits remotely sensed imagery, infrastructural data available at a municipal level, and object-based spatial analysis. For effective planning and management, the hierarchical levels of landscape classification (level 1), the analysis of use and cover by urban zones (level 2), and the fundamental elements of land cover (level 3), each exposes different respects relevant to city plans and management.
\end{abstract}

Keywords: Social-ecological hybridity, Object-based classification, High-resolution imagery, Ecosystem, Urban function zones, Land cover

\footnotetext{
* Correspondence: wzhou@rcees.ac.cn

'State Key Laboratory of Urban and Regional Ecology, Research Center for

Eco-Environmental Sciences, Chinese Academy of Sciences, Beijing 100085,

China

${ }^{2}$ University of Chinese Academy of Sciences, Beijing 100049, China

Full list of author information is available at the end of the article
}

\section{Springer Open}

(c) The Author(s). 2020 Open Access This article is licensed under a Creative Commons Attribution 4.0 International License, which permits use, sharing, adaptation, distribution and reproduction in any medium or format, as long as you give appropriate credit to the original author(s) and the source, provide a link to the Creative Commons licence, and indicate if changes were made. The images or other third party material in this article are included in the article's Creative Commons licence, unless indicated otherwise in a credit line to the material. If material is not included in the article's Creative Commons licence and your intended use is not permitted by statutory regulation or exceeds the permitted use, you will need to obtain permission directly from the copyright holder. To view a copy of this licence, visit http://creativecommons.org/licenses/by/4.0/. 


\section{Introduction}

Urban landscapes are highly heterogeneous in space, structurally and functionally (Band et al. 2005; Cadenasso et al. 2013; Zhou et al. 2014). The biophysical and socialeconomic heterogeneity are closely related to myriad urban problems, such as the urban heat island ( $\mathrm{Hu}$ et al. 2016; Huang et al. 2010; Oke 1982), urban air pollution (Briggs et al. 2000; Han et al. 2014; Rodríguez et al. 2016), threats to biodiversity (BINO et al. 2008; Nilon et al. 2011), and challenges to human health and well-being (Groenewegen et al. 2006). Mapping and quantifying the heterogeneity of urban structures and functions is crucial for understanding urban patterns, functions, and services, and finally for promoting urban management.

Remote sensing has long been used to quantify and map the spatial heterogeneity of the urban landscape, especially its biophysical structure at coarser scales. For example, medium and coarser-resolution remotely sensed images have been widely used to map and quantify urban expansion and associated land use/land cover changes, at scales from individual cities to regionals, and the globe (Hansen et al. 2000; Xian et al. 2009). In particular, numerous studies have mapped the intensity of impervious surfaces with different data sources and algorithms (Weng 2012; Zhang et al. 2013). With the growing availability of very high spatial resolution satellite imagery (e.g., 1-m IKONOS, 0.6-m QuickBird) and aerial photos/digital imagery, remote sensing has been increasingly used to map specific landscape features such as buildings, trees, and smallsized lawns, to understand the fine-scale spatial heterogeneity of urban landscapes (Lee et al. 2003; Ouma and Tateishi 2008; Zhou and Troy 2008).

Remote sensing has also long been used to map and quantify urban form from a functional perspective. The most common example of such perspective is land use mapping, from the simple "urban" versus "non-urban" mapping ( $\mathrm{Hu}$ et al. 2020; Jing et al. 2015) to more detailed within-urban land use classifications ( $\mathrm{Hu}$ and Wang 2013; Wu et al. 2006). Other interesting, but not so widely used classification systems include examples such as the Urban Structure Types (Voltersen et al. 2014; Wurm et al. 2009; Zhan et al. 2003), HERCULES classification scheme (Cadenasso et al. 2007), Ecotopes (Geerling et al. 2009), and Local Climate Zones (Middel et al. 2014; Stewart and Oke 2012).

Cities, or urban areas more broadly, are now widely recognized as social-ecological systems (McHale et al. 2015; Pickett et al. 2011), or social-ecologicaltechnological systems (Grimm et al. 2017). Therefore, a holistic approach that integrates the biophysical structure and social function is highly desirable to understand urban form. Here, we developed a three-level classification scheme and mapped those levels based on high spatial resolution imagery and a municipal census of building size, height, and usage using an object-based workflow. We aimed to reveal urban landscape from a comprehensive perspective and derive useful information for urban management.

\section{Materials and methods \\ Study area and data}

We chose Shenzhen, Guangdong Province, China (22 $26^{\prime}$

$\left.59^{\prime \prime}-22^{\circ} 51^{\prime} 49^{\prime \prime} \mathrm{N}, 113^{\circ} 45^{\prime} 44^{\prime \prime}-114^{\circ} 37^{\prime} 21^{\prime \prime} \mathrm{E}\right)$, as our study area. It is a highly developed city with a total administrative area of $1997 \mathrm{~km}^{2}$ (Fig. 1). Shenzhen is the first "Special Economic Zone" of China, established in 1978, and generating a GDP of more than 2000 billion yuan in 2019. In addition to economic development, Shenzhen has also put great effort into ecological conservation. For example, in 2005, Shenzhen created a "Basic Ecological Control Line" to restrict urban expansion, which has slowed down the loss of forests (Yu et al. 2019). The highly hybridized social and natural features in this city make it an ideal place to quantify urban form.

We used SPOT 6 (Satellite Pour l' Observation de la Terre, French for "Earth observation satellite") images from 2017 to map the hierarchical structure of the urban landscape (Fig. 1). SPOT 6 images consist of one panchromatic band, with $1.5-\mathrm{m}$ spatial resolution, and four multispectral bands, namely blue, green, red, and nearinfrared, with 6-m resolution. In addition, we also used the Shenzhen building census in 2015, which consists of 594,823 polygons for each building footprint, and contains the building height and the attribute of building use. The building census was obtained from the Bureau of Planning and Natural Resources.

\section{Hierarchical classification system}

We constructed a three-level classification system from a coarse to fine-scale, by considering various ways in which humans perceive and use urban landscape. Specifically, we first separated the urban ecosystem type from others such as forests and agriculture. We then mapped urban functional zones-hybrid patches that typically have a mixture of different land cover elements with built and non-built components within urban ecosystems. The different land cover elements within each patch type or zone were mapped (Fig. 2). In level 1, we separated the ecosystem types of urban, forest, wetland, grassland, and farmland. In level 2, we first classified urban function zones, namely residential, commercial, industrial, transportation, and mixed zones, within the urban ecosystem type. Any places not classified in one of the zones just mentioned were merged into a scenic zone. Within the scenic zone, we also separated transportation zones. In level 3, we differentiated eight land cover elements, namely tree canopy, grass, bare soil, water, building, road, impervious surface, and construction, within different types of zones. 


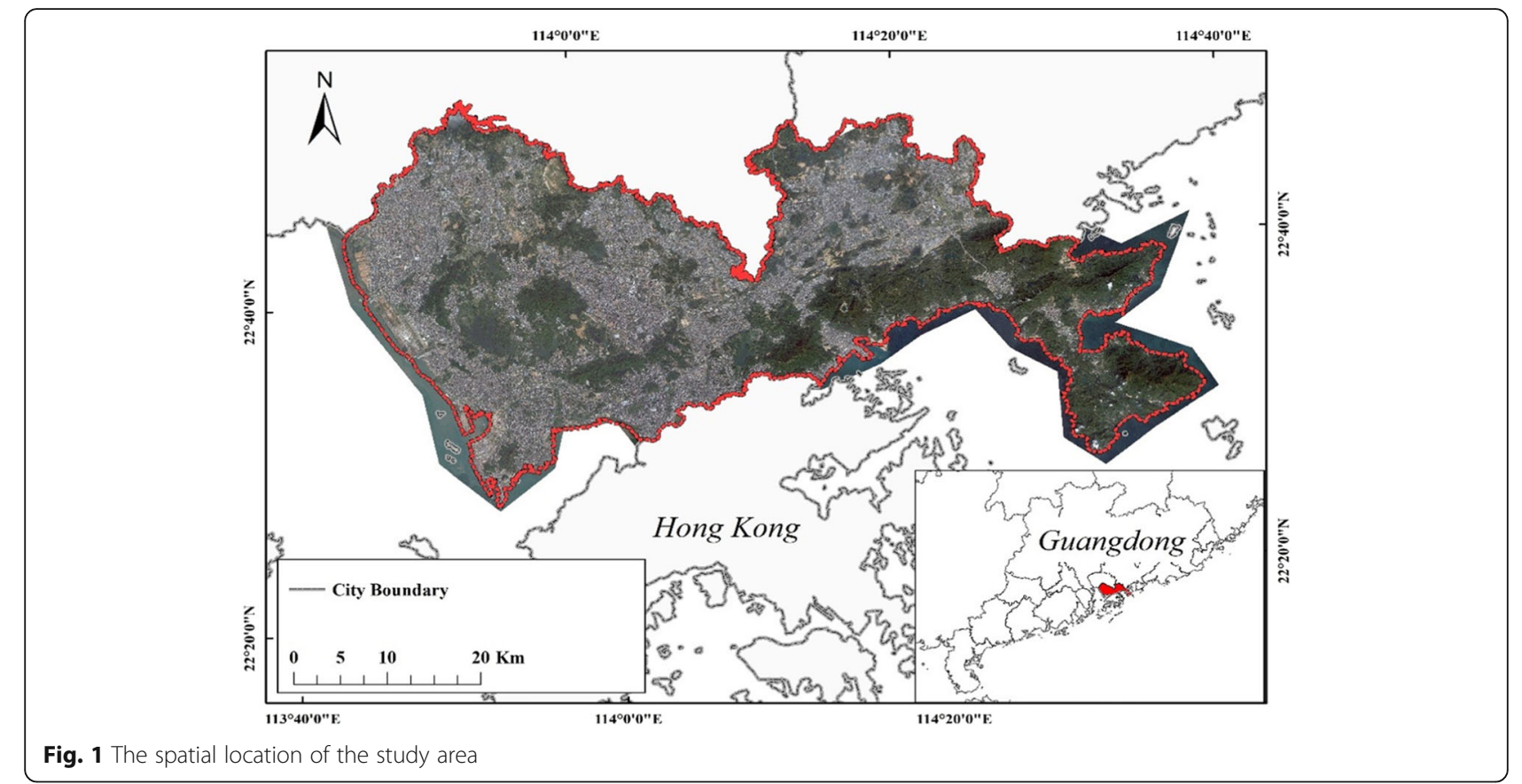

\section{Hierarchical classification methods}

We used a top-down classification procedure by conducting the classification in the order of ecosystem types, function zones, and land cover elements. The classification of the lower level was based on the results of the higher level. We used an object-based methodology to carry out the three-level classification. We segmented objects of multiple sizes to match the classification scales of different levels.

We first segmented the SPOT 6 image to generate large-scale objects of the first level and then used rulebased classification and visual interpretation to classify the objects. Based on the first level, we segmented the second level by overlaying the vector layer of blocks,

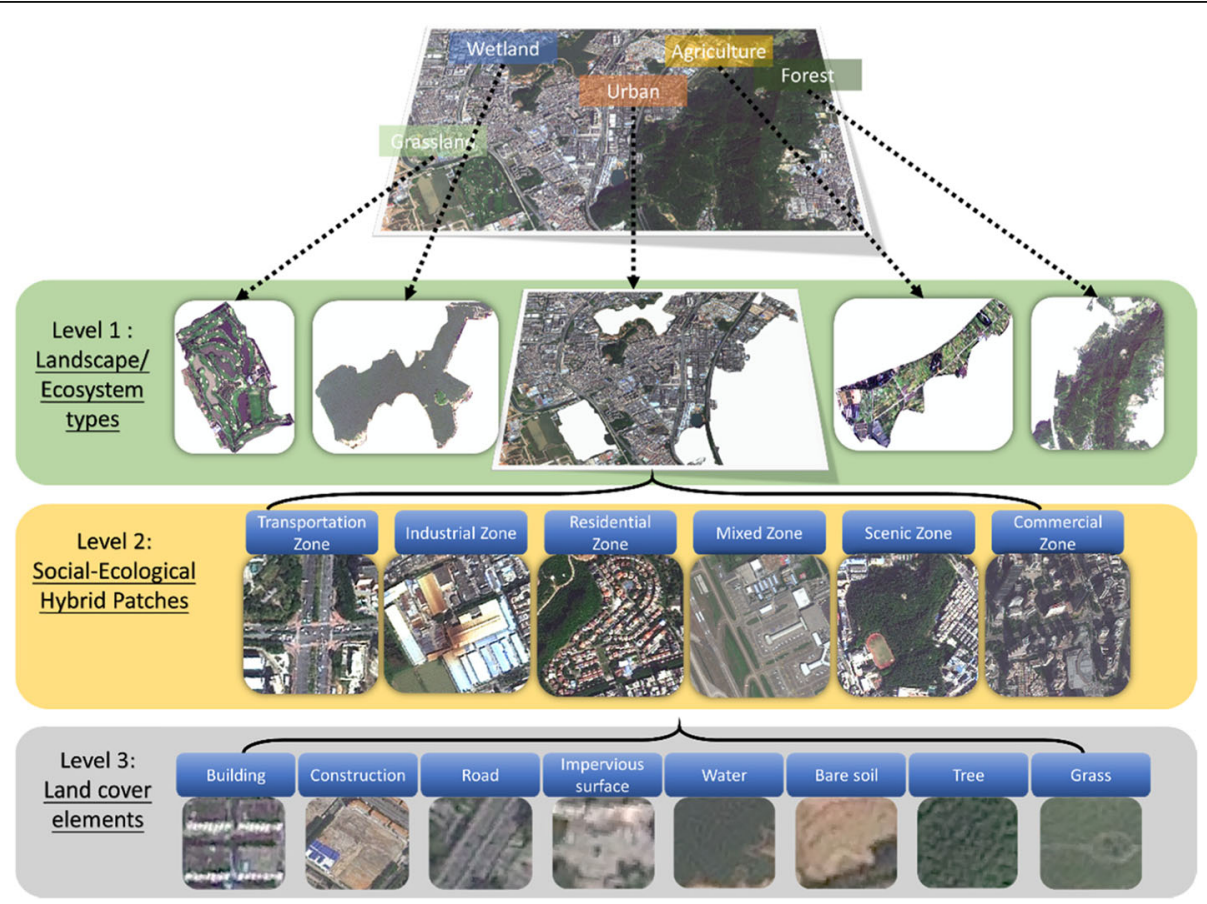

Fig. 2 The graphical example of the hierarchical classification system 
which was modified from the OpenStreetMap (www. openstreetmap.org), on the first level and classified the function zones in the second level using building attributes. Based on the second level, we segmented small objects of the third level and classified the land cover elements with supervised classification. During the classification, the classification results of the upper level provided information for the classification of the lower level, which referred to as a top-down feedback approach (Zhang et al. 2018).

\section{The first level: ecosystem types}

We used a multi-resolution segmentation algorithm (MRS) embedded in the eCognition ${ }^{\mathrm{TM}}$ software to segment the SPOT 6 image. This algorithm is a bottom-up segmentation method, which consecutively merges pixels with similar spectral features to generate objects. The spectral similarity of pixels is determined by the input image layers (Baatz and Schäpe 2000). Here, we set equal weights for the five original bands of SPOT 6 to calculate spectral similarity. The multi-resolution segmentation uses a parameter "scale" to determine the size of segmented objects. In general, the higher the scale value, the larger the size of the segmented object. In addition to the parameter scale, the multi-resolution segmentation uses two pairs of parameters: color and shape, and compactness and smoothness, to adjust the shape of segmented objects.

We first resampled the spatial resolution of the original image from 1.5 to $12 \mathrm{~m}$ to improve the segmentation efficiency. Then, we segmented large objects corresponding to the large patches of ecosystem types (Fig. 3). We set a large value of the scale parameter (450) by visually comparing segmentation results with different values from 200 to 600 . In addition, we set the weights of color and shape as 0.9 and 0.1 , respectively, and weighted both compactness and smoothness as 0.5 to segment meaningful boundaries, as suggested by previous studies (Mathieu et al. 2007; Pu et al. 2011).
After segmentation, we calculated the object features of normalized difference vegetation index (NDVI), normalized difference water index (NDWI), and brightness based on the original image (Table 1). Then, we categorized ecosystems using a rule-based classification. First, we classified the forest by setting an NDVI threshold larger than 0.22 . Second, we classified the wetland using a 0.17 threshold of NDWI. Third, we classified urban using a threshold of brightness set to larger than 530. Finally, we manually mapped grassland and farmland and improved classification results with visual interpretation. All threshold values were determined by the "trial and error" approach.

After classification, we further smoothed the borders of the objects by "sanding" the peninsulas, such as the long and thin roads which sprout from urban to forest ecosystems (Fig. 4), because those peninsulas were in fact belonging to the ecosystem enclosing them. Here, we used an algorithm called morphology embedded in eCognition ${ }^{\mathrm{TM}}$ to smooth the borders. We created a circle mask with a diameter of 6 pixels to sand the object. The parts of a single object were separated if the width of those parts were smaller than the mask and then reclassified to its surrounding context.

\section{The second level: urban function zones}

Based on the ecosystems' objects of the first level, we segmented the objects of the second level by overlaying the vector layer of the block (Fig. 5). Then, we classified urban function zones based on the classification results of the first level. First, we classified the scenic zones by merging ecosystems of forest, farmland, grassland, and wetland. Second, we extracted transportation zones in the whole Shenzhen based on the block layer. Third, we classified the urban ecosystem into residential, commercial, industrial, and mixed zones using the attribute of building usages.

For each building in the census, many attributes such as height, types, and usage were labeled by field

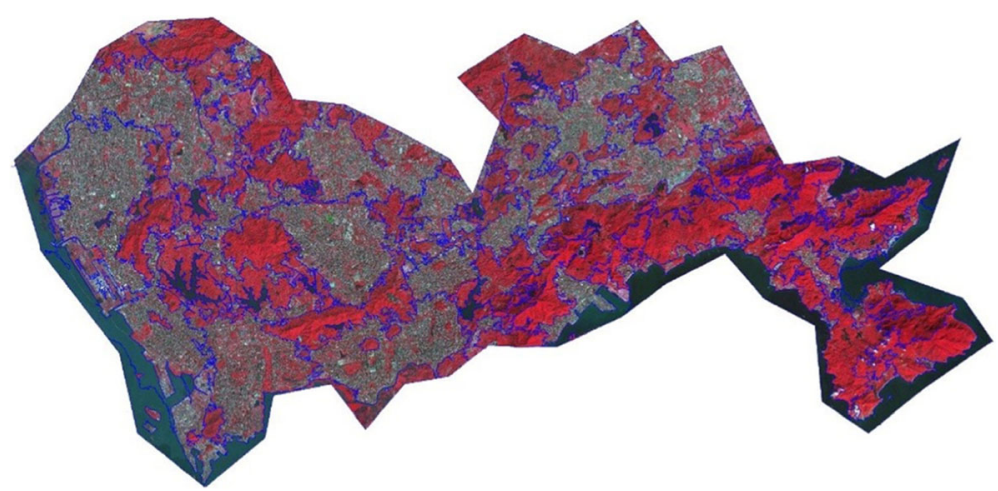

Fig. 3 The segmentation result of level 1 
Table 1 Object features used for classification

\begin{tabular}{ll}
\hline Object features & Description \\
\hline Mean value a $^{a}$ & Mean value of a specific band of an image object \\
Brightness & Average value of the 5 multispectral bands of an image object \\
Max. diff. & Max intensity difference of the 5 multispectral bands of an image object \\
NDVI & Mean value of the (NIR - red)/(NIR + red) of an image object \\
NDWI & Mean value of the (green - NIR)/(green + NIR) of an image object \\
Canny & Mean value of the Canny edge of an image object
\end{tabular}

${ }^{\mathrm{a}}$ Object features were calculated for each of the 5 original bands

investigation included in the census. Based on the attribution of usage, we categorized buildings into four basic types: residential, commercial, industrial, and others. For each object in the second level, we calculated the percentage of different building types and then classified the function zones according to the percentage of different building types. Specifically, if the percentage of one building type surpassed $50 \%$, then the object was classified as a zone of that building type. If the percentage of all building types were less than $50 \%$, the object will be classified as a mixed zone.

\section{The third level: land cover elements}

Within the objects of the second level, we further segmented the third level based on the original image with a spatial resolution of $1.5 \mathrm{~m}$ (Fig. 6). In addition, we used the vector layer of buildings as ancillary data to segment the boundary of the building footprint. We used a multiresolution segmentation algorithm and set the scale value as 120 to segment the relatively fine land covers. To segment objects along the boundary of land cover, we set more weights on color (0.9) and less weights on shape (0.1) and set equal weights for compactness (0.5) and smoothness (0.5), according to previous studies (Mathieu et al. 2007; Pu et al. 2011).

After segmentation, we classified roads and buildings based on the ancillary data. Then, we classified six land cover elements, namely tree canopy, grass, bare soil, water, impervious surface, and construction, using supervised classification. After that, we refined the results using a knowledge-based classification, which used the information of ecosystem types and function zones to improve the classification result. Finally, we conducted manual editing to refine the results, especially for construction and bare soil.

For the supervised classification, we first chose 30 training samples for each of the six classes referring to high spatial resolution imagery of SPOT 6 . Then, we chose NDVI, NDWI, brightness, canny edge, and original bands, as features for classification, which are commonly used in previous studies (Qian et al. 2014) (Table 1). Finally, we applied the classifier of the support vector machine (SVM) to classify different land cover elements. For SVM, we chose the RBF kernel, setting the parameter $C$ to $10^{6}$, and the parameter gamma to $10^{-5}$ as suggested in the previous study (Qian et al., 2014).

Subsequently, we conducted a knowledge-based classification by integrating expert knowledge to improve the classification. Specifically, we reclassified the land cover elements of the third level by considering the object characteristics of the upper levels of ecosystems and functions. For example, as previous research found that cloud shadows in the mountain areas are likely to be misclassified as water due to their spectral similarity (Amin et al. 2013; Li et al. 2013), we reclassified the water as tree canopy, if the corresponding object in the first level was classified as forest. Similarly, most water patches in the residential zones are most likely to be

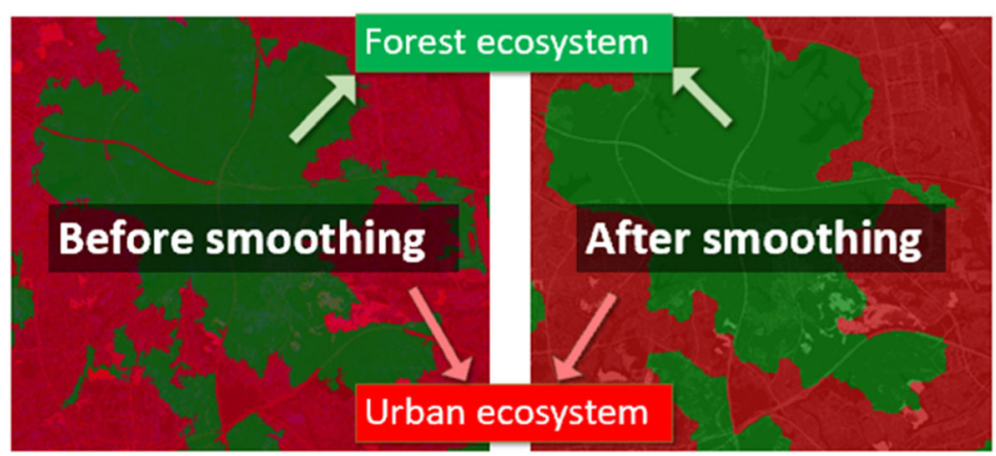

Fig. 4 An example of the smoothed objects by the morphology algorithm 


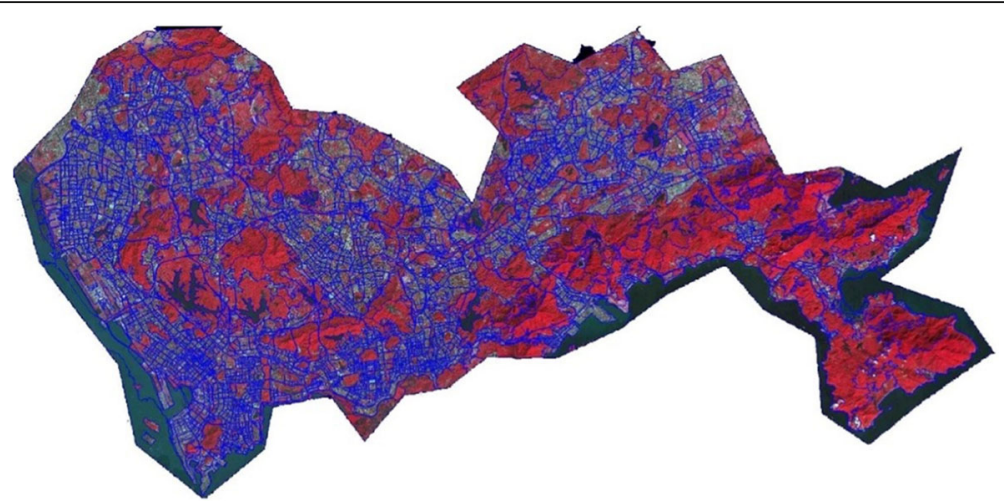

Fig. 5 The segmentation result of level 2

shadows cast by buildings (Zhao et al. 2009), so we corrected those instances of water to impervious surfaces if the corresponding object in the second level was classified as the residential zone.

\section{Accuracy assessment}

After the three-level classification, we conducted an accuracy assessment for the first and the third levels. We did not assess the accuracy of the second level, because its classifications were based on the ancillary data of roads and roofs, which are reliable results manually depicted based on field investigation of the census. For the first and third levels, we randomly selected 30 testing samples for each category based on SPOT 6 satellite imagery. Using the error matrix, we calculated the overall accuracy and the kappa coefficient.

\section{Results}

\section{Landscape pattern on the three levels}

The overall accuracies and kappa coefficient for the first level of the ecosystem were $91.3 \%$ and 0.89 , respectively.

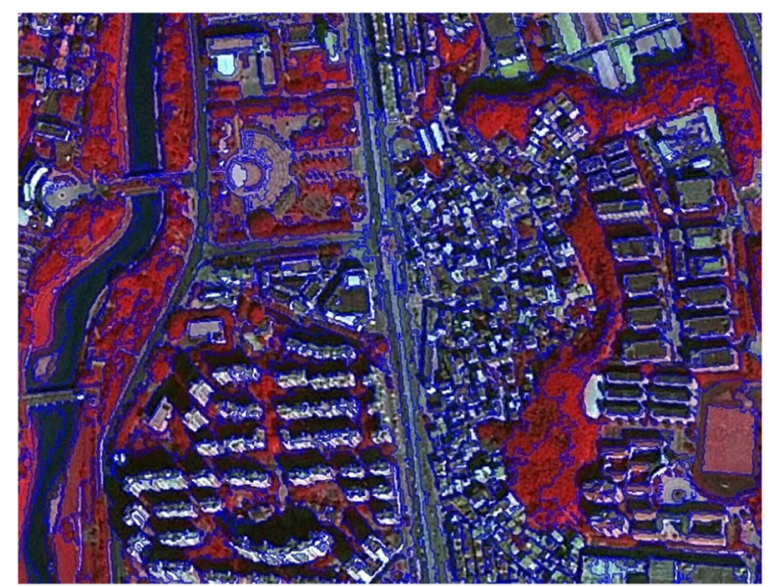

Fig. 6 The segmentation result of level 3
The classification on level 1 showed that the ecosystem types of forest and urban were the dominant ecosystems within the administrative boundaries of Shenzhen city, amounting to $51.4 \%$ and $45.3 \%$, respectively. Urban landscapes were located mostly in the western and northeastern parts of Shenzhen, while the forest landscapes were mainly distributed in the eastern Dapeng district of Shenzhen (Fig. 7, panel a). The proportions of the ecosystem types of wetland, farmland, and grassland were relatively small, accounting for only $2.3 \%, 0.6 \%$, and $0.3 \%$ of the whole city (Fig. 7 , panel a).

On the second level, the scenic zone was the dominant functional type, which accounts for $53.9 \%$ of the area, and was distributed throughout Shenzhen city (Fig. 7, panel b). The residential and industrial zones were also main functional types, which have proportions of $17.7 \%$ and $15.6 \%$, respectively. Within the urban ecosystem type, the proportions of residential and industrial zones were $38.4 \%$ and $33.8 \%$, respectively. The residential zones were distributed all over Shenzhen city, while the industrial zones were mainly located in the north, and many of them were connected with scenic zones (Fig. 7, panel $b$ ). The proportions of other functional zones were relatively small, with the proportions of mixed transportation, and commercial zones amounting to only $7.9 \%$, $3.7 \%$, and $1.3 \%$, respectively (Fig. 7 , panel b).

The overall accuracies and kappa coefficient for the third level of land cover were $87.5 \%$ and 0.86 , respectively. We found tree canopy was the dominant land cover element in Shenzhen, which accounted for 55.6\%. Second, building and impervious surfaces comprised $16.0 \%$ and $15.6 \%$ of Shenzhen. The next most abundant land cover elements were roads and water, which accounted for $5.0 \%$ and $4.5 \%$ of Shenzhen. The proportions of other land cover elements were relatively small, ranging from 0.6 to $1.7 \%$ (Fig. 7 , panel c).

\section{Landscape pattern from a multi-level perspective}

Comparing the land cover composition of different ecosystems, we found that the proportion of impervious 


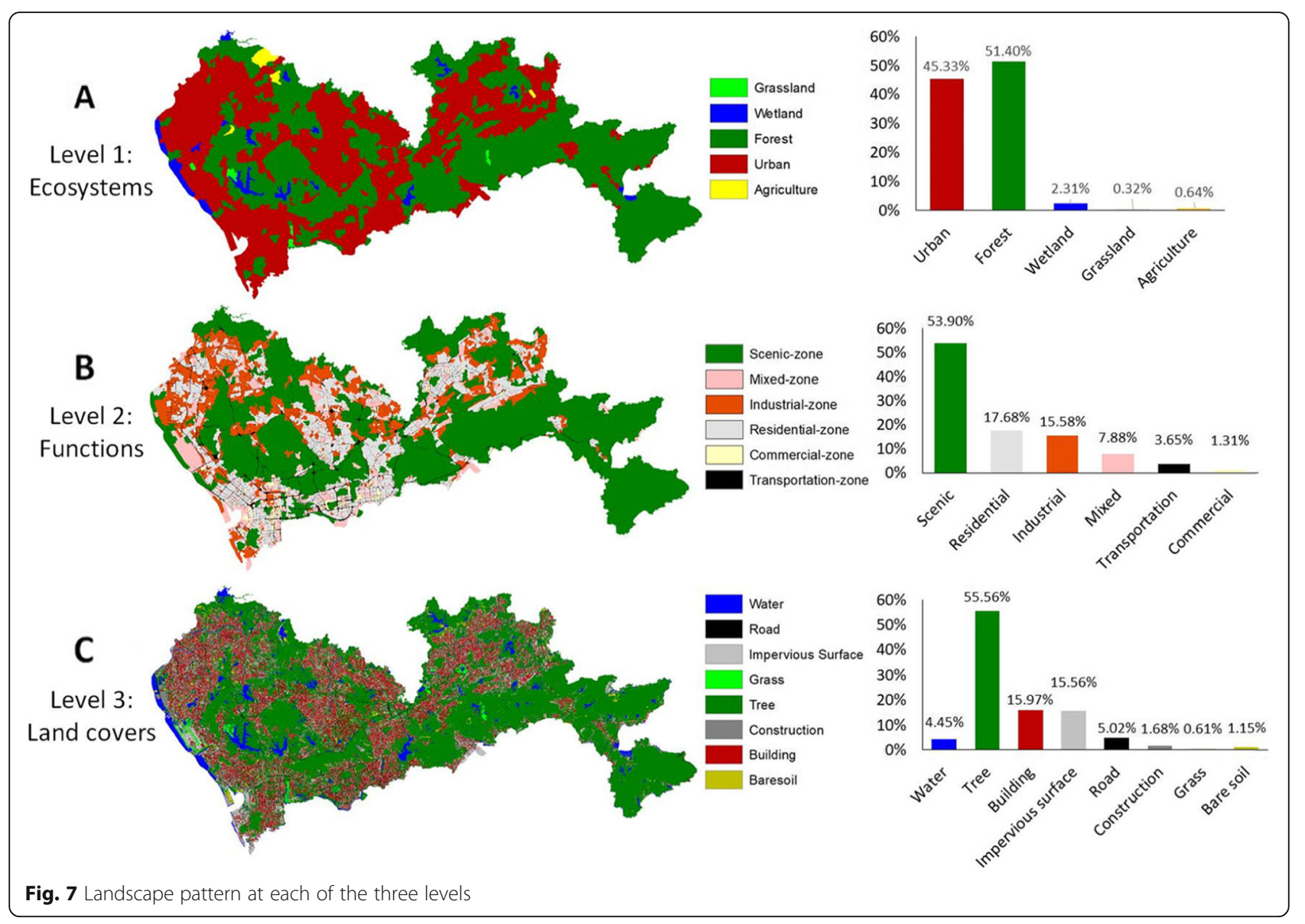

surface $(29.1 \%)$, buildings (32.2\%), and roads (9.6\%) was higher in urban ecosystems, while in other ecosystems, the proportion of impervious (less than 6.5\%), buildings (less than 6.0\%), and roads (less than 1.5\%) was much lower. In addition, the proportion of tree canopy in the urban ecosystem was also high (22.6\%), second only to the proportion of tree canopy $(85.8 \%)$ in the forest ecosystem (Fig. 8, panel a). From the perspective of the distribution of different land covers, we found most impervious surface (84.8\%), building (91.1\%), road (86.1\%), and construction lands (71.4\%) were distributed in the urban ecosystem, while the natural land cover elements such as tree canopy $(81.3 \%)$, water $(83.0 \%)$, grass (57.9\%), and farmland (80.5\%) were mostly located within non-urban ecosystem types (Fig. 8, panel b).

Comparing the land cover composition of different function zones, we found the mixed, residential, industrial, and commercial zones had a similar land cover composition (Fig. 8, panel c). All four zones had a large proportion of impervious surfaces, buildings, and trees. The total proportion of these three land cover elements was more than $80 \%$ (Fig. 8, panel c). Different from these four types of zone, the scenic zone was dominated by trees, which account for $81.6 \%$, while the transportation zone had a large proportion of roads, amounting to 51.6\% (Fig. 8, panel c). Combined with the distribution of different land covers (Fig. 8, panel d), we found that although the composition of the land covers in the mixed, residential, industrial, and commercial zones was similar, the areas of them were very different. Most buildings $(76.0 \%)$ and impervious surfaces $(62.1 \%)$ were located in residential and industrial zones, not the commercial zones (Fig. 8, panel d).

\section{Discussion}

Classification of urban systems began by distinguishing cities from the countryside (Pickett and Cadenasso 2009; Small et al. 2005) and has evolved to document the spread of urban land covers and land uses over expanding regions (Tan et al. 2010; Xiao et al. 2006). Land cover and land use (LC/LU) classifications, even with high-resolution imagery, consider large urban regions to be mosaics of distinct and sharply contrasting zones or districts. This can lead to confusion in understanding the very large administrative jurisdictions that characterize many megacities. Such large cities comprise vastly different landscapes that mix many specific habitat types. A first cut at understanding such extensive jurisdictions has been to identify and 


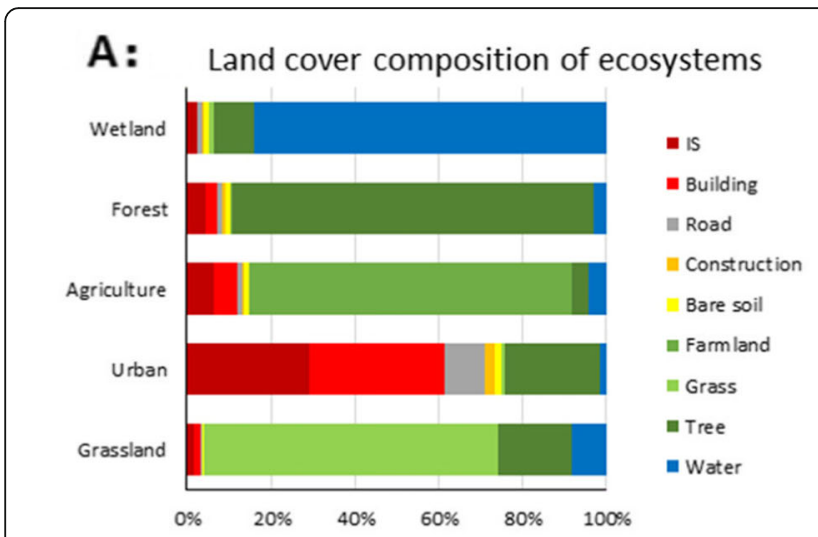

C: Land cover composition of function zones

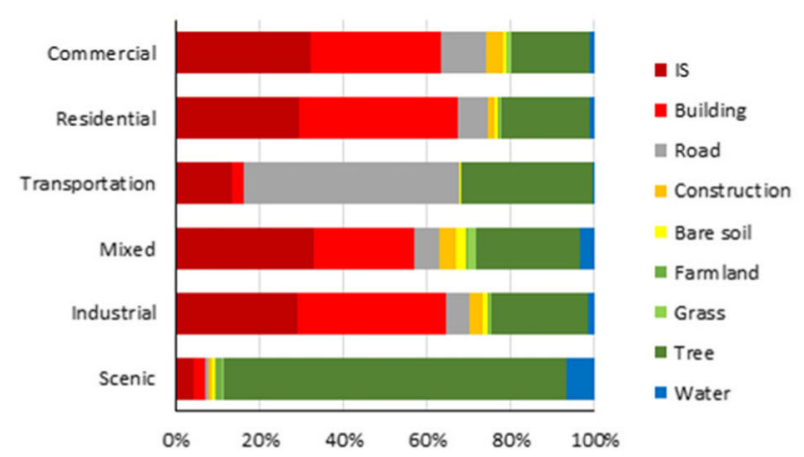

Fig. 8 Landscape pattern combining different levels

map the broadest landscapes or ecosystem types that exist within their boundaries (Fig. 3). Although functional zones can be recognized in cities, they are actually made up of specific, discrete cover types at lower hierarchical levels of the organization, though simultaneously contributing to the structure and function of the larger landscapes that exist in urban regions.

Our hierarchical classification system separates the urban system into three related levels: (1) ecosystem or landscape type, (2) functional zones, and (3) land cover elements. Land cover elements make up the functional zones, and the functional zones are distributed among contrasting landscape or aggregate ecosystem types. The different levels are connected using an object-based classification framework. Comparing to the traditional classification systems which mostly focused on one aspect of the many urban characteristics, such as urban area (Cao et al. 2009; Hu et al. 2020), urban structure types (Voltersen et al. 2014; Wurm et al. 2009), or land cover (Yu et al. 2016; Zhou et al. 2014), this new approach provides a comprehensive perspective and exposes massive "hidden" information by quantifying the pattern at and across multiple scales.

Take tree canopy as an example, previous studies were mainly interested in the percentage of tree canopy for the whole Shenzhen, which is $55.6 \%$ for Shenzhen city

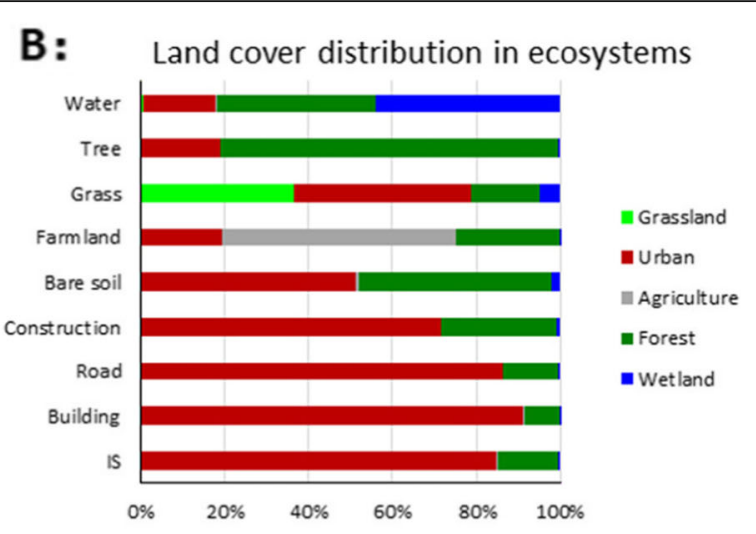

D: Land cover distribution in function zones

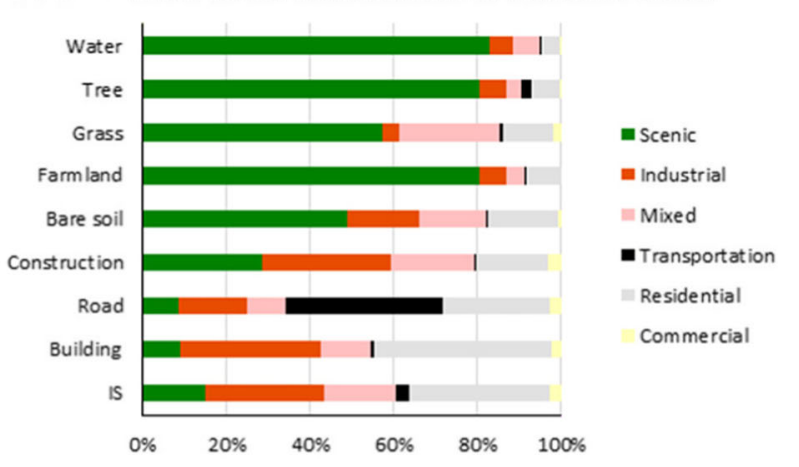

(Fig. 7, panel c). However, with the multi-level analysis, we found although tree canopy was the dominant land cover element in Shenzhen city, most trees $(80.7 \%)$ were located in the forest ecosystem type (Fig. 8, panel b). That led to a low percentage of the tree canopy (22.6\%) in the urban ecosystem type (Fig. 8, panel a), much lower than the percentage of buildings and impervious surfaces, which accounted for $32.2 \%$ and $29.1 \%$ of the urban ecosystems, respectively (Fig. 8, panel a). Similarly, most water $(83.0 \%)$ were distributed in the non-urban ecosystems; the percentage of water in the urban ecosystem type was $1.7 \%$, much lower than that in the whole city (4.5\%). Interestingly, we found that most of the construction lands $(71.4 \%)$ were distributed in the urban ecosystem, which indicates that there is a large proportion of internal renewal in Shenzhen.

By integrating the structures and functions, this approach can explore more classes of urban landscape according to our needs. For example, we can identify urban trees (18.7\%) and non-urban trees (81.3\%), which have different social-ecological processes and require different management, by combining level 1 and level 3 . Within the urban ecosystem, this approach can differentiate residential areas (level 2) based on building density, building height, and tree covers (level 3), which represent different living quality. In addition, this approach 
can create a massive spatial relationship when combining different classes, such as an industrial area next to the forest ecosystem.

That multiscalar information has great potential for urban management. For example, by analyzing the height and proportion of buildings in residential areas, we can identify shantytowns that might need urban renewal (Fig. 9, panel a). In addition, information on the percentage of trees in the patches can help urban managers rank the priority for urban revitalization. Furthermore, this approach can not only identify the area and location of forest or wetland ecosystems that merit protection, but also evaluate their ecological risks by analyzing their spatial distance from industrial zones (Fig. 9, panel b). Finally, in comparison to previous studies that mostly classified urban areas at a fixed spatial scale (Hu et al. 2020; Voltersen et al. 2014; Zhou and Troy 2008), this approach provides a flexible way of generating customized information at city, block, and patch scales. Such flexibility can support urban planning and management at corresponding scales.

This new approach has also improved the classification accuracy of urban land cover by using a top-down feedback approach (Zhang et al. 2018). That is, the classification results on the upper levels provided expert knowledge to assist the classification of the lower levels. For example, it corrected the misclassification of water as impervious surfaces in residential areas and corrected misclassification of some forest cover as water in the forest ecosystem. Previous studies often used expert knowledge of the land cover change to improve classification accuracy; for example, areas of impervious surface measured in early years of a study is unlikely to convert to water in later years ( $\mathrm{Yu}$ et al. 2016). This new approach, however, introduced the social-ecological information in classification and enlarged the application of the knowledge-based classification.

According to different research and management needs, this hierarchical framework can also be flexibly expanded or modified, especially for the socio-ecological hybrid patches of level 2. Take urban heat island (UHI) as an example. If we aim to study urban heat island intensity, we can analyze the temperature difference between the urban ecosystem landscapes and non-urban ecosystem in level 1 (Hu et al. 2016; Peng et al. 2018). In the urban ecosystem of level 1 , we can further subdivide the local climate zone (LCZ) to study the heat island within the urban area (Leconte et al. 2015; Stewart and Oke 2012). Within different LCZs, we can investigate the cooling effect of tree patches (Jiao et al. 2017; Qian et al. 2018). In addition to UHI, social-ecological patches of other types, such as urban structure types (Voltersen et al. 2014) or HERCULES (Cadenasso et al. 2007), can also be integrated into this framework.

\section{Conclusions}

This paper has taken the theoretical understanding of urban spatial heterogeneity and used it to generate a classification scheme that exploits remotely sensed imagery, infrastructural data available at a municipal level, and object-based spatial analysis. Applying the classification scheme to the megacity of Shenzhen has exposed the limitations of using data only at the scale of landscape or ecosystem type (level 1) in assessing, for

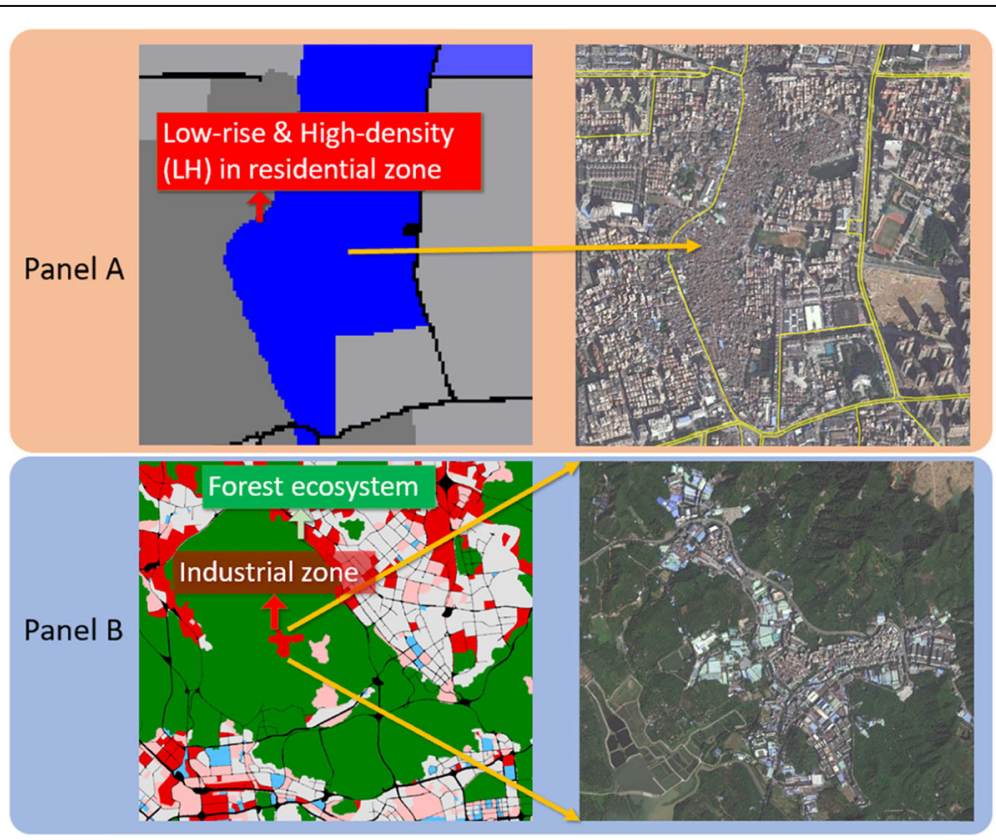

Fig. 9 Identifying urban hotspots by analyzing the pattern across levels 
example, the tree cover of the city. The hierarchical classification developed here has discovered that within the large urban landscape type, tree cover is actually less common than in city-wide data that include the four coarse landscape or ecosystem types. In other words, for effective planning and management, the hierarchical levels of landscape classification (level 1), analysis of use and cover by urban zones (level 2), and the fundamental elements of land cover (level 3), each exposes different respects relevant to city plans and management.

\section{Acknowledgements}

We thank the Shenzhen government for providing us with building census data to establish the hierarchical structure of the urban landscape. We also thank the two anonymous reviewers and editor in the journal Ecological Processes for their valuable and constructive comments.

\section{Authors' contributions}

Conceptualization: Yuguo Qian, Weiqi Zhou, and Steward T.A. Pickett; methodology: Yuguo Qian and Wenjuan Yu; validation: Dingpeng Xiong and Weimin Wang; formal analysis: Yuguo Qian; data curation: Wenjuan Yu; writing and original draft preparation: Yuguo Qian; writing, review, and editing: Weiqi Zhou and Steward T.A. Pickett; visualization: Chuanbao Jing; funding acquisition: Weiqi Zhou. All authors read and approved the final manuscript.

\section{Funding}

This research was funded by the National Key R\&D Program of China (Grant No. 2017YFC0505801), the National Natural Science Foundation of China (Grant No. 41771203 and 41601180), the Shenzhen Ecological Environment Bureau (Grant No. SZCG2018161498), and the Shenzhen Environmental Monitoring Center (Grant No. SZCG2018161442 and SZCG2017158233).

\section{Availability of data and materials}

The datasets used and/or analyzed during the current study are available from the corresponding author on reasonable request.

\section{Ethics approval and consent to participate}

Not applicable.

\section{Consent for publication}

Not applicable.

\section{Competing interests}

The authors declare that they have no competing interests.

\section{Author details}

'State Key Laboratory of Urban and Regional Ecology, Research Center for Eco-Environmental Sciences, Chinese Academy of Sciences, Beijing 100085, China. ${ }^{2}$ University of Chinese Academy of Sciences, Beijing 100049, China. ${ }^{3}$ Cary Institute of Ecosystem Studies, Box AB, Millbrook, NY 12545, USA. ${ }^{4}$ PowerChina Eco-environment Group Co., Ltd, Shenzhen 518102, China. ${ }^{5}$ Shenzhen Environmental Monitoring Center, Shenzhen 518049, China.

Received: 30 June 2020 Accepted: 30 September 2020

Published online: 27 October 2020

\section{References}

Amin R, Gould R, Hou W, Arnone R, Lee Z (2013) Optical algorithm for cloud shadow detection over water. IEEE Transactions on Geoscience \& Remote Sensing 51:732-741

Band LE, Cadenasso ML, Grimmond CS, Grove JM, Pickett STA (2005) Heterogeneity in urban ecosystems: patterns and process. In: Lovett GM, Turner MG, Jones CG, Weathers KC (eds) Ecosystem Function in Heterogeneous Landscapes. Springer, New York, NY. https://doi.org/10.1007/ 0-387-24091-8_13

Bino G, Levin N, Darawshi S, Van Der Hal N, Reich-Solomon A, Kark S (2008) Accurate prediction of bird species richness patterns in an urban environment using Landsat-derived NDVI and spectral unmixing. International Journal of Remote Sensing 29:3675-3700

Briggs D et al. (2000) A regression-based method for mapping traffic-related air pollution: application and testing in four contrasting urban environments. Science of the Total Environment 253:151-167

Cadenasso ML, Pickett STA, McGrath B, Marshall V (2013) Ecological heterogeneity in urban ecosystems: reconceptualized land cover models as a bridge to urban design. In: Cadenasso ML, Pickett STA, McGrath BP, Marshall $\checkmark$ (eds) Resilience in ecology and urban design: linking theory and practice for sustainable cities. Springer, Dordrecht

Cadenasso ML, Pickett STA, Schwarz K (2007) Spatial heterogeneity in urban ecosystems: reconceptualizing land cover and a framework for classification. Frontiers in Ecology and the Environment 5:80-88

Cao X, Chen J, Imura H, Higashi O (2009) A SVM-based method to extract urban areas from DMSP-OLS and SPOT VGT data. Remote Sensing of Environment 113:2205-2209 https://doi.org/10.1016/j.rse.2009.06.001

Geerling GW, Vreekenbuiijs MJ, Jesse P, Ragas AMJ, Smits AJM (2009) Mapping river floodplain ecotopes by segmentation of spectral (CASI) and structural (LiDAR) remote sensing data. River Research and Applications 25:795-813

Grimm NB, Pickett STA, Hale RL, Cadenasso ML (2017) Does the ecological concept of disturbance have utility in urban social-ecological-technological systems? Ecosystem Health and Sustainability 3:e01255

Groenewegen PP, Berg AEvd, Vries Sd, Verheij RA (2006) Vitamin G: effects of green space on health, well-being, and social safety. BMC Public Health 6:149

Han L, Zhou W, Li W, Li L (2014) Impact of urbanization level on urban air quality: a case of fine particles (PM2.5) in Chinese cities. Environmental Pollution 194:163-170

Hansen MC, Defries RS, Townshend JRG, Sohlberg RA (2000) Global land cover classi cation at $1 \mathrm{~km}$ spatial resolution using a classification tree approach. International Journal of Remote Sensing 21:1331-1364

Hu S, Wang L (2013) Automated urban land-use classification with remote sensing. International Journal of Remote Sensing 34:790-803 https://doi.org/ 10.1080/01431161.2012.714510

Hu X, Qian Y, Pickett STA, Zhou W (2020) Urban mapping needs up-to-date approaches to provide diverse perspectives of current urbanization: a novel attempt to map urban areas with nighttime light data. Landscape and Urban Planning 195:103709 https://doi.org/10.1016/j.landurbplan.2019.103709

Hu X, Zhou W, Qian Y, Yu W (2016) Urban expansion and local land-cover change both significantly contribute to urban warming, but their relative importance changes over time. Landscape Ecology 32:1-18

Huang G, Zhou W, Cadenasso ML (2010) Understanding the relationship between urban land surface temperature, landscape heterogeneity and social structure. In: IEEE International Geoscience \& Remote Sensing Symposium, IGARSS 2010, July 25-30, 2010, Honolulu, Hawaii, USA

Jiao M, Zhou W, Zheng Z, Wang J, Qian Y (2017) Patch size of trees affects its cooling effectiveness: a perspective from shading and transpiration processes. Agricultural and Forest Meteorology 247:293-299

Jing W, Yang Y, Yue X, Zhao X (2015) Mapping urban areas with integration of DMSP/OLS nighttime light and MODIS data using machine learning techniques. Remote Sensing 7:12419-12439

Leconte F, Bouyer J, Claverie R, Petrissans M (2015) Using local climate zone scheme for UHI assessment: evaluation of the method using mobile measurements. Building and Environment 83:39-49

Lee DS, Shan J, Bethel JS (2003) Class-guided building extraction from Ikonos imagery. Photogrammetric Engineering \& Remote Sensing 69:143-150

Li S, Sun D, Yu Y (2013) Automatic cloud-shadow removal from flood/standing water maps using MSG/SEVIRI imagery. International Journal of Remote Sensing 34:5487-5502

Mathieu R, Aryal J, Chong AK (2007) Object-based classification of Ikonos imagery for mapping large-scale vegetation communities in urban areas. Sensors 7:2860-2880

McHale MR et al. (2015) The new global urban realm: complex, connected, diffuse, and diverse social-ecological systems. Sustainability 7:5211-5240

Middel A, Hab K, Brazel AJ, Martin CA, Guhathakurta S (2014) Impact of urban form and design on mid-afternoon microclimate in Phoenix Local Climate Zones. Landscape \& Urban Planning 122:16-28

Nilon CH, Warren PS, Wolf J (2011) Baltimore birdscape study: identifying habitat and land-cover variables for an urban bird-monitoring project. Urban Habitats 6

Oke TR (1982) The energetic basis of the urban heat island. Quarterly Journal of the Royal Meteorological Society 108:1-24

Ouma YO, Tateishi R (2008) Urban-trees extraction from Quickbird imagery using multiscale spectex-filtering and non-parametric classification. ISPRS Journal of Photogrammetry \& Remote Sensing 63:333-351 
Peng J, Ma J, Liu Q, Liu Y, Hu Y, Li Y, Yue Y (2018) Spatial-temporal change of land surface temperature across 285 cities in China: an urban-rural contrast perspective. Science of the Total Environment 635:487-497

Pickett ST, Cadenasso ML (2009) Altered resources, disturbance, and heterogeneity: a framework for comparing urban and non-urban soils. Urban Ecosystems 12:23-44

Pickett STA, Buckley GL, Kaushal SS, Williams Y (2011) Social-ecological science in the humane metropolis. Urban Ecosystems 14:319-339

Pu R, Landry SM, Yu Q (2011) Object-based urban detailed land cover classification with high spatial resolution IKONOS imagery. Journal of Remote Sensing 32:3285-3308

Qian Y, Zhou W, Hu X, Fu F (2018) The heterogeneity of air temperature in urban residential neighborhoods and its relationship with the surrounding greenspace. Remote Sensing 10:965

Qian Y, Zhou W, Yan J, Li W, Han L (2014) Comparing machine learning classifiers for object-based land cover classification using very high resolution imagery. Remote Sensing 7:153-168

Rodríguez MC, Dupont-courtade L, Oueslati W (2016) Air pollution and urban structure linkages: evidence from European cities. Renewable \& Sustainable Energy Reviews 53:1-9

Small C, Pozzi F, Elvidge CD (2005) Spatial analysis of global urban extent from DMSP-OLS night lights. Remote Sensing of Environment 96:277-291 https://doi.org/10.1016/j.rse.2005.02.002

Stewart ID, Oke TR (2012) Local climate zones for urban temperature studies. Bulletin of the American Meteorological Society 93:1879-1900

Tan KC, San Lim H, MatJafri MZ, Abdullah K (2010) Landsat data to evaluate urban expansion and determine land use/land cover changes in Penang Island. Malaysia Environmental Earth Sciences 60:1509-1521

Voltersen M, Berger C, Hese S, Schmullius C (2014) Object-based land cover mapping and comprehensive feature calculation for an automated derivation of urban structure types at block level. Remote Sensing of Environment 154:192-201 https://doi.org/10.1016/j.rse.2014.08.024

Weng Q (2012) Remote sensing of impervious surfaces in the urban areas: requirements, methods, and trends. Remote Sensing of Environment 117:3449

Wu SS, Xu B, Wang L (2006) Urban land-use classification using variogram-based analysis with an aerial photograph. Photogrammetric Engineering \& Remote Sensing 72:813-822

Wurm M, Taubenbock H, Roth A, Dech S (2009) Urban structuring using multisensoral remote sensing data: by the example of the German cities Cologne and Dresden. In: 2009 Joint Urban Remote Sensing Event

Xian G, Homer C, Fry J (2009) Updating the 2001 National Land Cover Database land cover classification to 2006 by using Landsat imagery change detection methods. Remote Sensing of Environment 113:1133-1147. https://doi.org/ 10.1016/j.rse.2009.02.004

Xiao J, Shen Y, Ge J, Tateishi R, Tang C, Liang Y, Huang Z (2006) Evaluating urban expansion and land use change in Shijiazhuang, China, by using GIS and remote sensing. Landscape and Urban Planning 75:69-80

Yu W, Zhang Y, Zhou W, Wang W, Tang R (2019) Urban expansion in Shenzhen since 1970s: a retrospect of change from a village to a megacity from the space. Physics and Chemistry of the Earth. Parts A/B/C 110:21-30. https://doi.org/10.1016/j.pce.2019.02.006

Yu W, Zhou W, Qian Y, Yan J (2016) A new approach for land cover classification and change analysis: integrating backdating and an object-based method. Remote Sensing of Environment 177:37-47

Zhan Q, Molenaar M, Tempfli K (2003) Hierarchical image object-based structural analysis toward urban land use classification using high-resolution imagery and airborne LIDAR data. Proceedings of the Remote Sensing and Data Fusion over Urban Areas, IEEE/ISPRS Joint Workshop, 2002

Zhang H, Zhang Y, Lin H (2013) A comparison study of impervious surfaces estimation using optical and SAR remote sensing images. International Journal of Applied Earth Observations \& Geoinformation 18:148-156

Zhang X, Du S, Qiao W (2018) Integrating bottom-up classification and top-down feedback for improving urban land-cover and functional-zone mapping. Remote Sensing of Environment 212:231-248

Zhao L, Yu H, Zhang L (2009) Water body extraction in urban region from high resolution satellite imagery with near-infrared spectral analysis. SPIE 7383:125

Zhou W, Mary C, Kirsten S, Steward P (2014) Quantifying spatial heterogeneity in urban landscapes: integrating visual interpretation and object-based classification. Remote Sensing 6:3369-3386
Zhou W, Troy A (2008) An object-oriented approach for analysing and characterizing urban landscape at the parcel level. International Journal of Remote Sensing 29:3119-3135

\section{Publisher's Note}

Springer Nature remains neutral with regard to jurisdictional claims in published maps and institutional affiliations.

\section{Submit your manuscript to a SpringerOpen ${ }^{\circ}$ journal and benefit from:}

- Convenient online submission

- Rigorous peer review

- Open access: articles freely available online

- High visibility within the field

- Retaining the copyright to your article

Submit your next manuscript at $\boldsymbol{\nabla}$ springeropen.com 